$\frac{232 / 1 / 4}{1 / 1 / 4062-M S}$

\section{Informal Report}

\section{Uranium Mill Monitoring for \\ Natural Fission Reactors}

iti. 1752

UC-11

Issued: December 1977

K. E. Apt

\title{
- InOS
}

soientific laboratory

of the University of California

LOS ALAMOS, NEW MEXICO 87545

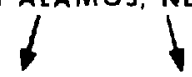

An Alfirmative Action/Equal Opportunily Employer 
URANIUM MILL MONITORING FOR NATUPAL FISSION REACTORS

by

K. E. Apt

\section{ABSTRACT}

Isotopic monitoring of the product stream from operating uranium mills is proposed for discovering other possible natural fission reactors; aspects of their occurrence and discovery are considered. Uranium mill operating characteristics are formulated in terms of the total uranium capacity, the uranium throughput, and the dilution half-time of the mill. The requirements for detection of milled reactorzone uranium are expressed in terms of the dilution half-time and the sampling frequency. Detection of different amounts of reactor ore with varying degrees of $235 \mathrm{U}$ depletion is considered. For an episodic introduction of reacter ore into a mill, the detection threshold of the isotopic anomaly using "grab" sampling is compared to that using continuous sampling. For a continuous introduction of reactor ore, the detection threshold for a "steady-state" concentration of anomalous uranium is determincd, and times required for processing reactor zones are estimated. Mill monitoring schemes which are most sensitive to initial episodes of reactor ore throughput are recommended, but the operating characteristics of a given mill influence the choice of type and frequency of sampling. The effectiveness of monitoring schemes is investigated in terms of the analytical sensitivity of the isotopic analysis and the sampling specifics. Systematic uranium mill monitoring should be effective in discovering other natural fission reactors.

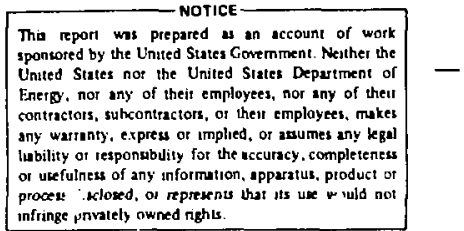




\section{INTRODUCTION}

The Ok1o natural fission reactor is one of the Earth's most intriguing puzzles. ${ }^{1}$ This "fossilized" nuclear pile, discovered 2,3 fortuitously by isotopic analysis of a urarium sample, has been the subject of a large international investigation involving many scientific disciplines. Results of these studies ${ }^{4}$ have extended our knowledge of uranium geochemistry, reactor waste-product geochemistry, isotope geology, and the broader subject of the geochemistry of the primordial Earth. The extent of natural fission reactor phenomena in Precambrian times, however, is still an unknown. We know that there was at least one natural reactor system, but the possibility of other systems has only been guessed at. Nevertheless, if other reactors occurred, their discovery and elucidation would provide further understanding of these timely geologic problems. This report demonstrates how monitoring the product of uranium mills that refine ore from Proterozoic, vein-type deposits could lead to the discovery of other natural fission reactors.

\section{OTHER POSSIBLE NATURAL REACTORS}

In considering the likelihood of finding other natural fission reactors, at least three probabilities come to mind. The first is the probability of a reactor actually forming in Precambrian uranium ores. The second is the probability of a natural reactor surviving intact for times of 1 to 2 billion years (b.y.). And the third is the probability of our detecting a phencmenon in mining or processing operations. Our finding a natural reactor is governed by the product of these individual probabilities, but unfortunately, the Oklo event is the only example with which we can assess these probabilities. For Oklo, the detection was very circumstantial, and the probability of detection was therefore very luw. Even if we assume the probability for the survival of Precambrian ores to be $100 \%$, then there must have been a relatively large number of natural reactors formed in Precambrian times for us to observe this one event of oklo. If this conjecture is true, a concerted effort should result in evidence for other intact reactors similar to $0 k 10$, and perhaps evidence for reactors which have not survived intact but have been geologically dispersed. 
For natural reactors to form, certain requirements $1,5,6$ must have been met: they could have formed only in uranium accumulations that are greater than 20.6 b.y. old, highly concentrated with uranium content $>20 \%$, and relatively large with minimum dimensions around $1 \mathrm{~m}$. Older uranium ores are more likely to have hosted natural reactors because the relative abundance of the fissile ${ }^{235_{U}}$ was greater in past aeons. (At the time of the oklo event $1.8 \mathrm{~b} . \mathrm{y}$. ago, the relative abundance in natural uranium was $3 \%$, whereas it has undergone radioactive decay to the present relative abundance of $0.7 \%$.) Thus, for highly concentrated Precambrian deposits, there was a greater overall concentration of the ${ }^{235} \mathrm{U}$ in the assemblage. Larger deposits would retain more of the fissionproduced neutrons which sustain the chain reaction. The presence of water and the relative absence of neutron-absorbing trace elements would have been required for a chain reaction, but it is difficult to establish whether these conditions existed in a Precambrian ore configuration.

Many of these conditions for a natural reactor may have been common in Proterozoic, "vein-type" uranium deposits. During the Proterozoic period (about 0.6 to 2.6 b.y. ago), a major change in the earth's chemistry may have contributed to the formation of mas sive uranium veins. Early in this period there had been major orogeny and subsequent weathering which provided a large "reservoir" of unoxidized sediments. Later, microbial life evolved to an aerobic stage and gradually increased the oxygen content of the atmosphere and oceans. Reduced uranium $\left(\mathrm{UO}_{2}\right)$ in the sediments and surface rocks was then oxidized to the hydrochemically mobile uranyl state. Once released into the ground water, uranyl complexes were free to migrate to chemicaliy reducing regions where the uranium precipitated as uraninite or related pitchblende. Where this process took place in large cavities or porous regions, massive uranium mineralization often resulted. Sich structurally controlled uranium vein deposits of the Proterozoic are the most likely locations for natural fission reactors.

Proterozoic mineral deposits are easily accessible only in regions where the Precambrian continental shields are exposed. As 
shown in Fig. 1, these are regions which have not experienced sedimentary cover or orogeny during the Phanerozoic period. The most extensive Precambrian shield exposures are in central and southern Africa, northern Canada, eastern South America, and portions of Australia and Eurasia. Of these regions, important Proterozoic, vein-type uranium deposits are found in the Alligator Rivers region of the Northern Territory, Australia; northern Saskatchewan and the Northwest Territories, Canada; and Zaire and Gabon, Africa. of course, most of the uranium associated with vein-type deposits of these regions is not distributed in large, rich veins which would have been conducive to a natural reactor. But these deposits often contain such zones of uranium mineralization that are worthy of investigation.

Like a modern light-water reactor, a natural fission reactor derives most of its power from the fission of ${ }^{235} \mathrm{U}$. The "burnup" of the ${ }^{235} \mathrm{U}$ fuel, and the resulting depletion of ${ }^{235} \mathrm{U}$, are approximately proportional to the magnitude of the natural reactor event. But unfortunately the $235 \mathrm{U}$ depletion is not a direct proportionality. $\Lambda$ s with a modern reactor, a natural reactor can operate in a "conversion" mode where ${ }^{235} \mathrm{U}$ expended in fission is replenished by the following conversion reaction:

$$
{ }^{238} \mathrm{U}(\mathrm{n}, \gamma){ }^{239} \mathrm{U} \stackrel{\beta}{\longrightarrow}{ }^{239} \mathrm{~Np} \stackrel{\beta}{\longrightarrow} 239 \mathrm{Pu} \stackrel{\alpha}{\longrightarrow} 235_{\mathrm{U}}
$$

Consequently, the net ${ }^{235}$ U depletion will be something less than the actual $235_{U}$ spent, and the natural reactor will exhibit some "effective burnup" which is cqual to this net depletion of ${ }^{235} \mathrm{U}$. The conversion ratio ( ${ }^{239} \mathrm{U}$ production to $235_{\mathrm{J}}$ depletion) characterizes the reaction of Eq.(1). At Ok10 this ratio was 20.4 . Of the $\approx 30$ tons of $235_{U}$ originally present in the oklo reactor zones, 26.6 tons underwent fission or neutron capture ( $21 / 6$ of the fission rate), but another 2.6 tons were produced via conversion. The average effective burnup for the reactor zones was $\sim 13 \%$, even though certain regions with $>50 \%$ depletion of ${ }^{235} U$ were observed.

It has been postulated ${ }^{1,6}$ that for certain younger Precambrian ore configurations, the conversion in a natural reactor could be so 


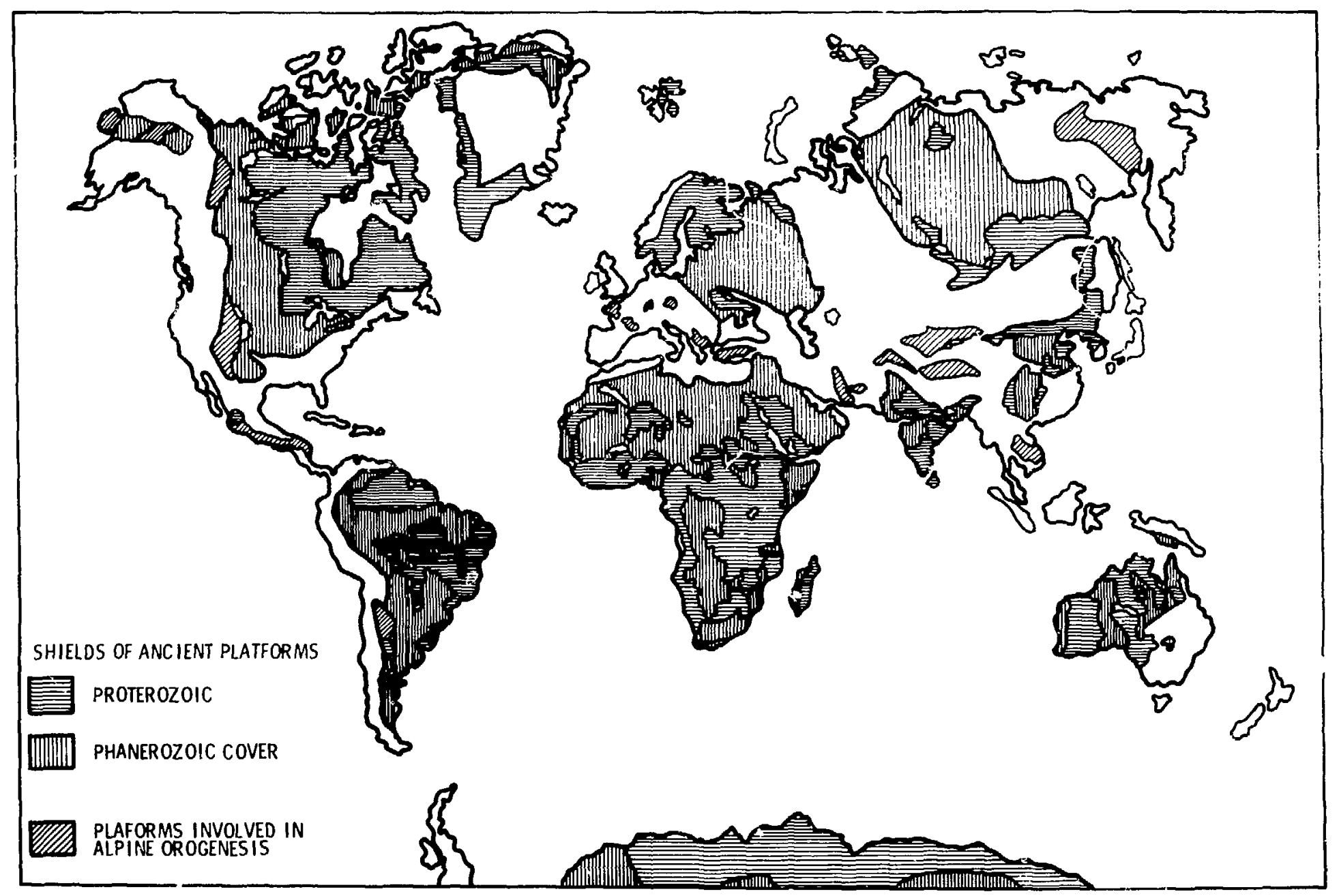

Fig. 1.

Tectonic map showing Precambrian continental shield areas of the world with areas of sedimentary cover and regions involved in alpine orogenesis. 
great that there would actually be a slight increment in the ${ }^{235} \mathrm{U}$ content, despite extensive fission of this species. Such a natural "breeder" reactoi would not exhibit a ${ }^{235} \mathrm{U} /{ }^{238} \mathrm{U}$ ratio significantly different from the normal value, and uranium isotopic monitoring would be ineffective in detecting this cvent. This possibility is not considered in this report because the physical requirements for such a natural breeder reactor are very restrictive, and they are much less likely to have been met comparad to thcse requirements for an oklo-type reactor. Consequently, the most straightforward way to detect a natural fission reactor is to ooserve an isotopic depletion of ${ }^{235} \mathrm{U}$ in uranium extracted from a natural reactor zone.

\section{URANIUM MILL. MONITORING METHODOLOGY}

One way to discover other natural fission reactors is to analyze uranilim ore samples from high-grade zones located in Proterozoic, vein-type depusits. Samples obtained from exploration drill core and hand specimens from mines are best suited for an initial survey of this type. Isotopic measurement of a deficit of ${ }^{235} \mathrm{U}$ (or perhaps an increment of fission-product elements, e.g., ruthenium, paliadium, or rare-earth elements) in these samples would be evidence for a fossilized natural reactor. Such anilyses are being conducted $^{7,8}$ for uranium deposits of northern Saskatchewan, the Alligator Rivers region of Australia and for other worldwide locations; but no isotopic anomalies have been detected.

It is not surprising that additional natural reactors have not been discovered by this survey tєchnique. Exploration core and mine specimens represent a very small fraction of an ore body, and a fossilized reactor zone could very easily be missed during drilling or inadequately sampled during mining. While these survey tech. niques could prove very useful, a more thorough monitoring technique is obviously needed. A program of systematic sampling and analysis of the output from selected uranium mills would fill this need.

Uranium ore milling and processing is generally conducted by "continuous" rather than "batch" processes. Ore is constantly fed into a mill at some optimum level which is determined by the capacity and specific refinement process of the mill. Once uranium ore 
is mined, there are several points in the process stream which tend to mix uranium, thereby diluting any possible natural reactor uranium. These points include ore stockpiling, ore crushing and sizing, chemical leaching of uranium from the ore matrix, uranium purification by chemical extraction, and concentration of final "yellowcake" $\left(\mathrm{U}_{3} \mathrm{O}_{8}\right)$ product by precipitation. In general, there is one large mixing vess $21, \mathrm{e} . \mathrm{g}$. , the $\mathrm{U}_{3} \mathrm{O}_{8}$ precipitator tank, which contains several times the quantity of uranium contained in any of the other stages. The precipitator would typically contain several days' uranium output, whereas the 20 or so other stages would contain a small fraction of this amount.

Uranium mills usually process a few thousand tons of ore per day with a continuous yellowcake output of several tons per day. Ore grades entering a mill are kept relatively constant at values between about 0.1 and $0.5 \% \mathrm{U}_{3} \mathrm{O}_{8}$, depending on the particular mill process. If anomalous ore (i.e., ore containing ${ }^{235} \mathrm{U}$-depleted uranium from a natural reactor) enters a mill process stream, it will be continuously diluted, but the anomaly wili be reflected in the mill output for some time afterward. The extent of the anomaly in the yellowcake output depends on many process parameters that will be considered later. Nevertheless, it would seem that systematic sampling and isotopic analysis of yeliowcake product would be able to detect an anomaly at some reasonable level of input into the mill.

It is impossible to predict exactly how anomalous uranium ore from a natural reactor will be introduced into a mill. However, two limiting cases will be considered here: the first is that of a single quantity of anomalous ore being introduced episodically into the process stream; the second is a cuntinuous input of a constant concentration of anomalous ore. Actual milling of natural reactor ore will no doubt be some variation of these two cases. The detectability of an actual event can therefore be estimated if the detectabilities of these two cases are known quantitatively.

The detection of a uranium isotope anomaly in mill output, of course, depends on the sensitivity of the analysis procedure being employed. Gas $\left(\mathrm{UF}_{6}\right)$ mass spectrometry is currently the most precise 
uranium isotopic measurement technique available. With a precision of 20.01 relative per cent, gas mass spectrometry can determine ${ }^{235} \mathrm{U}$ weight percent (wt. $\frac{0}{0}$ ) values which are accurate to within about 1 part in 7000 , e.g., $0.7110 \pm 0.0001 \mathrm{wt} . \%$. However, the natural vai.iability of the ${ }^{235} \mathrm{U}$ relative abundance is greater than the range of uncertainty for gas mass spectrometry. The $235_{U}$ content in natural uranium (excluding ok1o) has a worldwide variability 9 from about 0.7103 to about $0.7112 \mathrm{wt} . \%$. Most magmatic ores have values around $0.7108 \mathrm{wt} . \stackrel{0}{0}$, whereas those for the sandstone deposits of the Colorado Plateau and Niger are about $0.7106 \mathrm{wt} . \%$. The worldwide average is about 0.7107 wt. $\frac{\circ}{6}$ with one standard deviation, $u$, of about 0.0002 wt. $\%$. A uranium sample with a ${ }^{235} \mathrm{U}$ content lower, by 30 or more, than the average will then be treated as an anomaly resulting from a natural reactor; the analytical threshold for detecting an isotopic anomaly is thus $\leq 0.7101 \mathrm{wt} . \% 235^{\mathrm{U}}$. A. The Case of Anomalous Ore Introduced Exisodical1y in a Mi11 Process

If a uranium mill can contain a total mass $M$ of uranium and the anomalous uranium has mass $m$, then at introduction into the mill process the anomalous uranium will be diluted by the factor $\mathrm{m} / \mathrm{M}$. (To a first approximation, the total capacity of a uranium mill can be described by the quantity $M$. which is about equal to the quantity of uranium in the largest mixing step of the mil1.) Progressively, the output of the mill will contain a decreasing content of the depleted uranium, and the $235_{U}$ content will increase toward the norial value of about 0.7107 wt. . The rate at which the altered uranium will be purged from the mill is dependent on the rate of uranium throughput, $R$, for the mill and on the total quantity of uranium being processed. The quantity $R$ depends on the chemical yield of the mill but is taken to be equal to the mill uranium output. These rates are typically a few metric tons of uranium per day. Likewise, typical values of $M$ are several tons.

For the mass $m$ of affected uranium (not ore), the decrease in concentration of $\mathrm{m}$ in the total mass $M$ can be described by:

$$
\mathrm{d} m / \mathrm{d} t=-\lambda \mathrm{m}
$$


where $\lambda$ is a dilution constant. The solution of Eq. (2) is the wellknown exponential function:

$$
m=m_{o} e^{-\lambda t} \text {, }
$$

where $m_{0}$ is the initial mass of affected uranium in the dilution process, and $t$ is the time after the addition of the affected ore. The "half-time," $t_{\frac{1}{2}}$, of the dilution described by Eq. (3) is defined as the time required for the concentration of anomalous uranium to be reduced by one-half. That is,

$$
t_{\frac{1}{2}}=(\ln 2) / \lambda \text {. }
$$

Since $\lambda$ is equal to $R / M$,

$$
t_{\frac{1}{2}}=(\ln 2) \mathrm{N} / \mathrm{R} \text {. }
$$

In the event there are two or more mixing vessels which contain the iargest single quantities of uranium in the mill, the concentration of anomalous uranium in the output is governed by a series of differential equations involving the $\lambda$ 's of these vessels. The Bateman solution describes the simultaneous differential equations. But put simply, two or more major mixing vessels would decrease the peak of an isotopic anomaly in the cutput but would extend it over a longer time. The Batcman solution is not considered further since the mathematical treatment with one vessel provides a conservative prediction for grab sampling and is very similar to the treatment of multiple vessels for continuous sampling. For continuous anomaiy input, the predictions are the same.

The uranium isotopic alteration of the mill output is a function of dilution half-time, the initial quantity of affected uranium, $m_{o}$, and finally the extent of ${ }^{235} \mathrm{U}$ depletion in the affected reactor ore. The effective per cent burnup of ${ }^{235} U$ is designated as $B$. If we assume for the moment that the reactor ore entering the process stream would be $30 \%$ depleted in $235_{U}$, then the ${ }^{235} U$ content (relative to total uranium) of the output is shown in Fig. 
2 as a function of time after introduction of the anomalous ore. The three curves correspond to initial concentrations $\mathrm{C}_{0}\left(=\mathrm{m}_{0} / \mathrm{M}\right)$ of $10 \%, 5 \%$, and $1 \%$.

By way of illustrating Fig. 2, consider the detection of 200 $\mathrm{kg}$ of anomalous uranium with effective burnup $B=30 \%$ that is introduced to a process plant with uranium output of 4 tons per day and with a total capacity of 8 tons of uranium. The 4 tons per day output corresponds to about $10^{3}$ tons of ore input, whereas the 200 $\mathrm{kg}$ of reactor uranium would be from less than one ton of ore becaluse of the high uranium concentrations required for reactor formation. Four days after the anomaly input, the ${ }^{235_{U}} \mathrm{U}$ content of the product would be about $0.7100 \mathrm{wt}$. $\frac{\circ}{n}$ which would be barely distinguishable from the expected isotope content of $0.7107 \mathrm{wt} . \%$. The dilution half-time in this example is about 1.4 days, and after 6 days the anomaly would not be observable in the product because of analytical limitations and natural uranium isotopic variability. This natural variability is represented graphically in Fig. 2 by the dashed region (i.e., $0.7107 \pm 0.0006$ wt.\%); isotope ratios within this region would be indistinguishable from normal uranium. We see that for the above example, the anomaly is fairly rapidly washed out, and the event could easily go undetected.

The data of Fig. 2 can be used to estimate the sensitivity of isotopic measurement of "grab" samples in detecting natural reactor uranium in a mill process stream. The concentration of anomalous uranium in the total mill uranium is given by

$$
C=C_{0} e^{-\lambda t}
$$

where $C=m / M$ and $t$ is the time after introduction of the reactor uranium. Now the ${ }^{235} \mathrm{U}$ wt.\% of the grab sample is given by:

$$
\text { wt. } \begin{aligned}
\circ & =\mathrm{C}(1-\mathrm{B} / 100) 0.7107 / 100+(1-\mathrm{C} / 100) 0.7107 \\
& =0.7107\left(1-\mathrm{CB} / 10^{4}\right)
\end{aligned}
$$

where both $C$ and $B$ are in per cent. With a detection threshold of $0.7101 \mathrm{wt} . \%$ and a grab-sample frequency given by $\mathrm{T}_{\mathrm{g}}$, Eq. (6) can be 


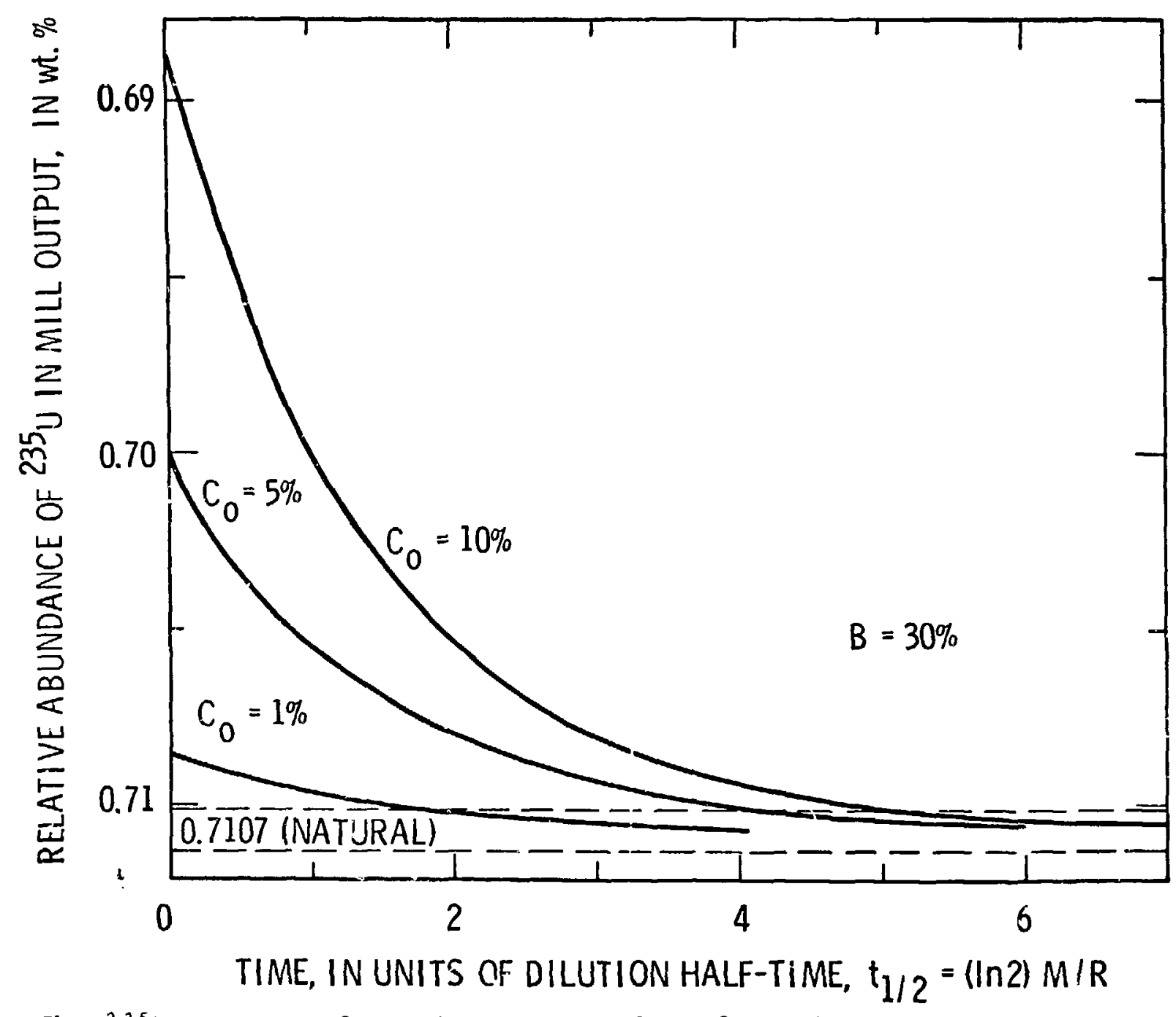

Fig. 2. The ${ }^{2}{ }^{35} \mathrm{U}$ content of uranium mill product following the introduction of a quantity of $m$ of ${ }^{235} \mathrm{U}$-depleted uranium in a mill with total uranium capacity of $M$. The depleted uranium is from natural reactor ore which has an effective ${ }^{235} \mathrm{U}$ burnup of $B$, the initial concentration $C_{0}$ is equal to $n / M$, and the mill has a uranium throughput rate of $R$. 
rewritten in terms of the requirements of $C_{0}$ and $B$ necessary for detection of an event with the worst possible timing of $t=T_{g}$. That is,

$$
B C_{0} \geq(8.44) \exp \left[(\ln 2) \mathrm{T}_{\mathrm{g}} / \mathrm{t}_{\frac{3}{2}}\right],
$$

where $B$ and $C_{0}$ are both given in per cent. Equation (7) sets the mininum limit for detection via grab sampling, and Fig. 3 portrays this limit.

For a typical mill with a mixing half-time of two days and an outpui of 4 tons of uranium per day, Fig. 3 indicates that weekly grab sampling could be assured of observing an event with $C_{0}$ greater than $9.5 \%$ where effective burnup is $10 \%$. This would mean that $C_{0}$ must correspond to about 1.1 tons of anomalous uranium in the system. This is a very large amount of reactor uranium. Recalling that the total reactor zones at Oklo were only 800 tons of uranium with an average $B$ of about $13 \%$, it is conceivable that a ton of high-grade reactor ore could be mined at a given time. But the mixing associated with ore stockpiling, grading, and blending would make it very unlikely that such a quantity would be iniroduced into the mill process stream at any one time.

A more thorough method of uranium mill monitoring would be to continuously collect a sample of the ore input or the yellowcake output. The technique would in theory collect some small fraction of all uranium which passes through the mill. Representative samples of ore "heads" are often taken at "custom" mills which must strictly account for ores from customer mining companies. Other continuous assay samples are often collected further along in the process stream. Ideally, a continuous representative sample of the mill yellowcake product would require the least amount of sample preparation and handing prior to uranium isotopic analysis.

The ${ }^{235_{U}}$ isotopic concentration of the continuously collected sample is a function of duration of collection, $\mathrm{T}_{\mathrm{C}}$, initial concentration in the process stream, $C_{0}=m_{0} / M$, the effective burnup, $B$, and the mill mixing half-time, (1ni)M/R. Also, the time at which the anomalous ore is introduced into the mill relative to the start 


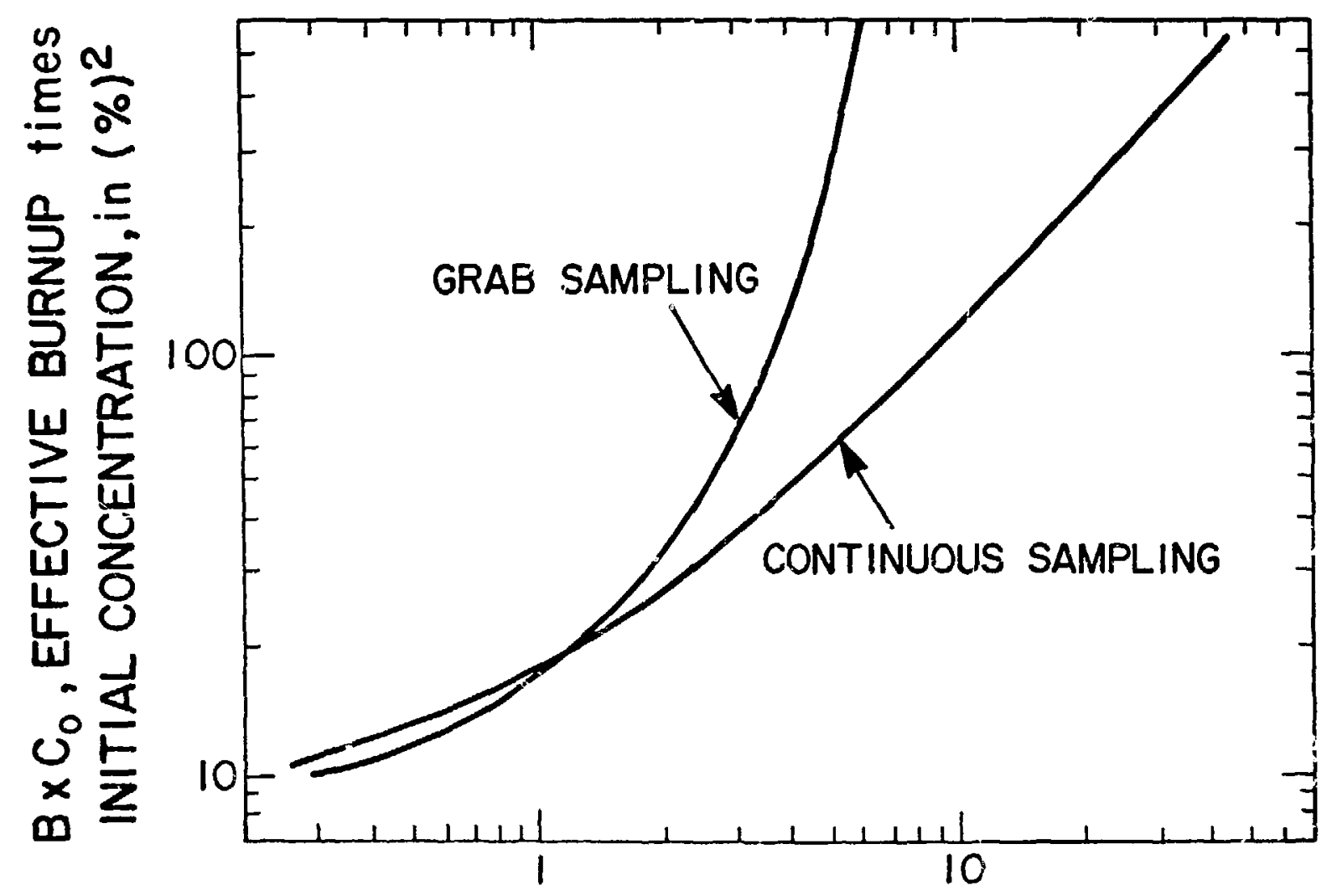

$T / t_{1 / 2} ; G R A B-S A M P L E$ FREQUENCY (OR CONTINUOUS SAMPLE DURATION ) DIVIDED BY DILUTION HALF-TIME

The detection curves for natural Fig. 3.

The detection curves for natural reactor uranium that is introduced episodically, with the worst possible timing, in the sampling cycle. 
of the continuous sample is important. The concentration $\bar{C}$ of anomalous uranium in the continuously collected uranium is given by

$$
\begin{aligned}
\bar{C} & =\frac{1}{T_{C}} \int_{0}^{T} C d t=\frac{1}{T_{C}} \int_{0}^{T} C_{1} e^{-\lambda t} d t \\
& =\frac{C_{1} M}{R_{C}}\left(1-\exp \left[-R T_{c} / M\right]\right),
\end{aligned}
$$

where $C_{1}$ is the concentration of anomalous uranium in total uranium, $M$, at the outset of sample collection and some time after anomaly introduction into the process stream [from Eq. (5)]. The final $235_{U}$ weight per cent of the continuous sample (taking $0.7107 \mathrm{w \tau} . \%$ as norma1) is

$$
w t . \frac{0}{0}=0.7107\left(1-\frac{10^{-4} \mathrm{MBC}_{1}}{\mathrm{RT}_{C}}\left(1-\exp \left[-\mathrm{RT}_{C} / \mathrm{M}\right]\right)\right) \text {, }
$$

where $B$ and $C_{1}$ are both in per cent.

To illustrate Eq. (9), if there are 4 tons of uranium in a mill extraction vessel, and the plant throughput is 4 tons per day, then $40 \mathrm{~kg}$ (i.e., $\mathrm{C}_{1}=1 \%$ ) of reactor uranium with $\mathrm{B}=30 \%$ would be undetectable for continuous sampling times longer than about 3.5 days. Clearly, for greater values of $\mathrm{C}_{1}$ (or, interchangeably, greater values of $B$ ) the continuous sampling time could be longer with no loss of detectability. As with grab sampling, continuous sampling is more effective for mills with longer half-times.

For continuous and contiguous mill sampling, a uranium anomaly can be detected in consecutive samples. The later in a collection cycle the anomaly first appears, the less effect there will be in that particular sample but the greater the effect in the subsequent sample. Consequently, there is a time of introduction after the outset of sampling when the isotopic alteration will be the same for the two consecutive samples. This critical time $t^{-}$is depicted in Fig. 4 ; $t^{\prime}$ is a function of $T_{c}$ and $t_{k}$ but not of $C_{o}$ or $B$. 


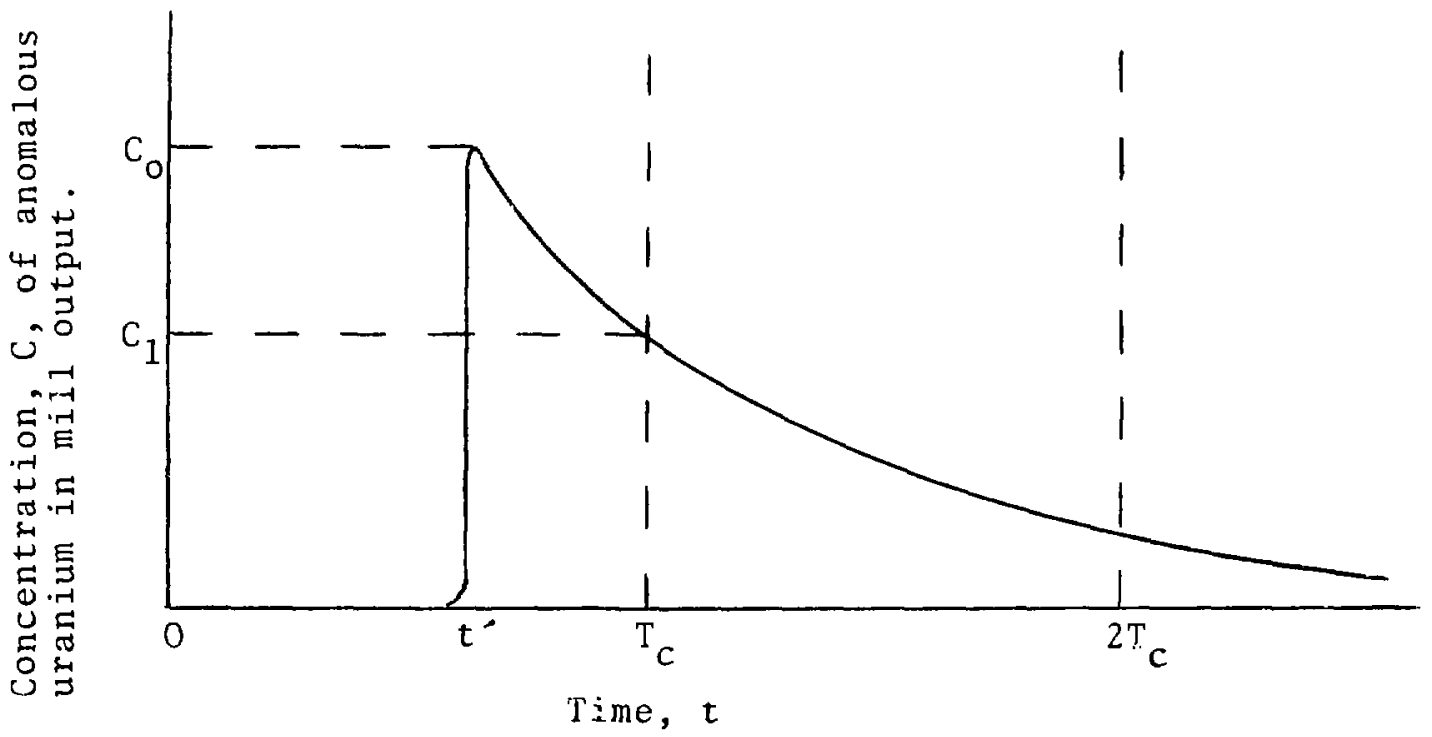

Fig. 4 .

The critical time $t^{\prime}$ in continuous sample collection.

The critical time $t^{\prime}$ can be found by setting the integral of $C$ in the first sample equal to the integral of $C$ in the second sample; that is,

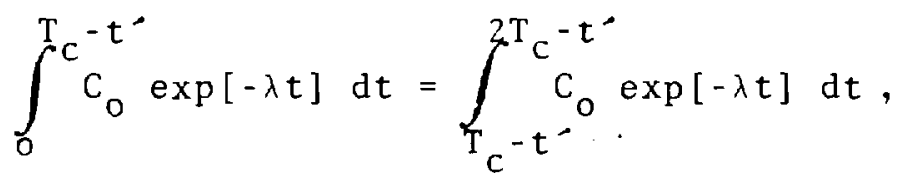

from which it follows that

$$
\begin{aligned}
t^{-} & =T_{c}-\ln \left(2-\exp \left[-\lambda T_{c}\right]\right) / \lambda \\
& =T_{c}-t_{\frac{1}{2}} \ln \left(2-\exp \left[-(\ln 2) T_{c} / t_{\frac{1}{2}}\right]\right) / \ln 2 .
\end{aligned}
$$

The critical time, $t^{*}$, can be used to obtain the value of the minimum isotopic alteration of the two consecutive samples. In other words, $t^{-}$sets the limit of detectability of the continuous uranium isotopic monitoring technique. Hence, the ${ }^{235} \mathrm{U}$ weight per cent of the second sample (which will be equal to the first sample) is given by 


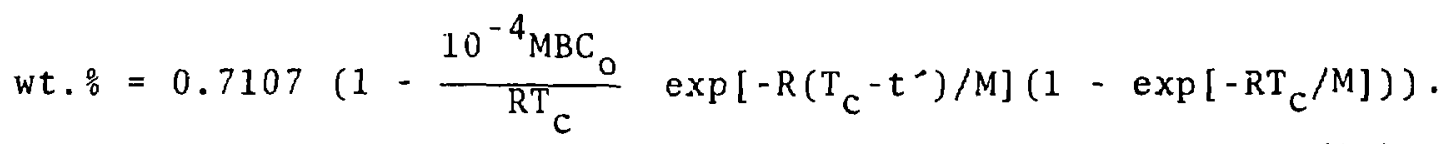

If the anomaly detection threshold is again $0.7107 \mathrm{wt} . \%$, then the requirements of $C_{0}$ and $B$ are given as follows:

$$
\begin{array}{r}
C_{c} B \geq(8.44)(\ln 2)\left(\frac{T_{c}}{t_{\frac{1}{2}}}\right)\left(2-\exp \left[-(\ln 2) T_{c} / t_{\frac{1}{2}}\right]\right) / \\
\left(1-\exp \left[-(\ln 2) T_{c} / t_{\frac{1}{2}}\right]\right) .
\end{array}
$$

Equation (13) establishes the requirements of $C_{0}$ and $B$ for detection of natural reactor uranium by continuous monitoring. Figure 3 depicts these requirements in terms of the ratio of continuoussampling time, $T_{c}$, to dilution half-time, $t_{t_{2}}$. For example, for collection times equal to the $t_{2}$ of the mill process, guaranteed detection of a $20 \%$ effective burnup ore would require about $0.8 \%$ of the initial uranium in the mixing vessel to be from the natural reactor zone. If the collection time were five times the half-time, the required $\mathrm{C}_{0}$ would be about $3 \%$. Considering the monitoring example referred to for grab sampling $\left(t_{\frac{3}{2}}=2 d, T_{c}=7 d\right.$, and uranium output aquals 4 tons/d), we see that the detection limit of $\mathrm{C}_{\mathrm{O}} \mathrm{B}$ is $43(\%)^{2}$ instead of $95(\%)^{2}$. Hence, about $\geq 500 \mathrm{~kg}$ of $10 \%$ burnup uranium (instead of $\geq 1$ ton) would have to be introduced into the mill to insure detection. Continuous sampling more than doubles the detection capability for this example.

In addition to determining the requirements for detecting an event with the worst sampling timing, we may consider the requirements of $\mathrm{C}_{\mathrm{o}}$ and $\mathrm{B}$ for detection of an anomaly with average timing. In other words, how do grab sampling and continuous sampling compare when the anomaly occurs midway between grab samples or midway in a continuous sample. The requirements of $\mathrm{C}_{\mathrm{o}}$ and $\mathrm{B}$ for grab sampling are given by Eq. (7) where $T_{g}$ is replaced by $T_{g} / 2$, and the requirements for continuous sampling are given by 


$$
C_{0} B \geq(8.44)(1 n 2)\left(T_{c} / t_{\frac{1}{2}}\right) /\left(1-\exp \left[-(\ln 2) T_{c} / 2 t_{\frac{1}{2}}\right]\right) .
$$

Figure 5 depicts these requirements graphically; the isotopic detection threshold is again taken as 0.7101 wt. $\%$. The discontinuity for the continuous sampling curve results from the situation where $t^{-}<T_{c} / 2$. That is, for very long dilution half-times, the perturbation of the second continuous sample is greater than the first. The requirements of $\mathrm{C}_{0}$ and $\mathrm{B}$ for the second continuous sample are given by the solid curve for $T_{c} / t_{\frac{1}{2}}<1.4$.

The effectiveness of grab sampling versus continuous sampling can be directly compared using Figs. 3 and 5 . In Fig. 3 , the anomaly introduction occurs just after collection of the grab sample or at the critical time for continuous sampling. For these worst cases, if the grab-sampling frequency or continuous-sampling duration is less than about twice the mill half-ime, there is essentially no difference between the two methods. However, for ratios of $\mathrm{T}_{\mathrm{g}} / \mathrm{t}_{\frac{1}{2}}$ and $\mathrm{T}_{\mathrm{c}} / \mathrm{t}_{\frac{1}{2}}$ greater than two, continuous sampling is obviously superior. When this ratio is $5: 1$, continuous sampling is five times more effective, and for ratios greater than about 10:1, grab sampling is incapable of detecting any quantity of anomalous ore. For a 10:1 ratio, however, continuous sampling could still guarantee detection of an event with $\mathrm{BC}_{\mathrm{O}} \geq 100(\%)^{2}$.

In Fig. 5, where the anomaly is introduced midway in a collection cycle, grab sampling is superior for sampling time:halftime ratios less than about $4: 1$. Above this value, the effectiveness of grab sampling rapidly deteriorates, but continuous sampling remains feasible for ratios in excess of $10: 1$.

B. The Case of Anomalous Uranium Ore Introduced Continuously in a Mill Process

The preceding arguments apply to the detection of natural reactor uranium where the affected uranium is introduced episodically to the process mill. By contrast, we can consider anomalous reactor uranium which is fed into the mill continuously over a relatively long time. The anomalous uranium concentration of the mill product would then be expressed in terms of the amount of affected uranium in the mill, $m$, the half time, $t_{\frac{1}{2}}=(\ln 2) / \lambda$, and 


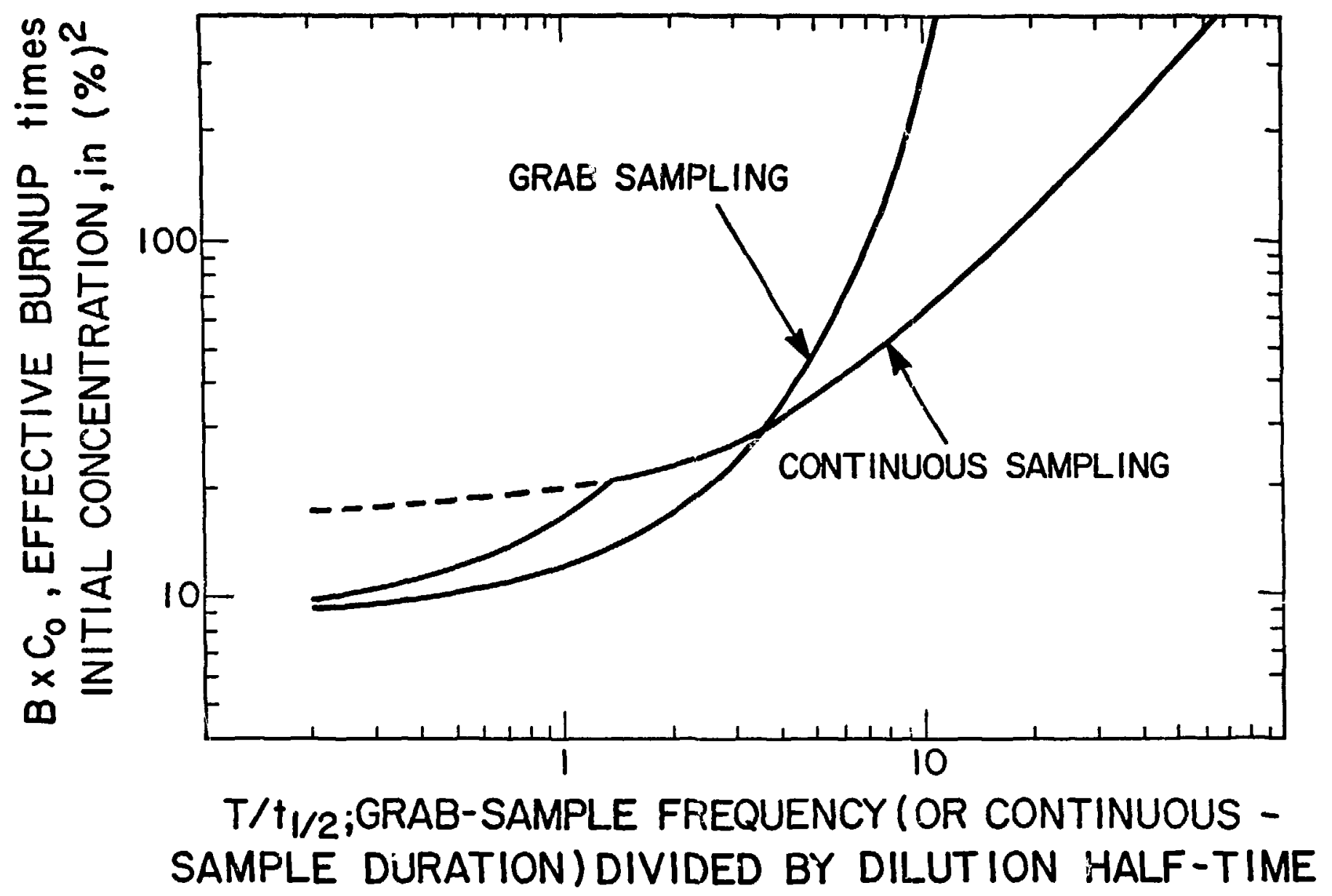

Fig. 5 .

The detection curves for natural reactor uranium introduced episodically midway in a sampling cycle. 
the rate, $k$, at which the anomalous uranium is fed into the mill. (It is assumed that $k$ does not vary with time.) The equation

$$
\mathrm{dm} / \mathrm{dt}=\mathrm{k}-\lambda \mathrm{m}
$$

describes the change in $m$ with respect to time, and the solution of Eq. (15) is

$$
\mathrm{m}=\frac{\mathrm{k}}{\lambda}\left(1-\mathrm{e}^{-\lambda t}\right)
$$

The anomalous uranium concentration in the output is given by:

$$
C=m / M=\frac{k}{\lambda M}\left(1-e^{-\lambda t}\right) .
$$

For a continuous feed situation, a "steady state" will occur when the amount of affected uranium entering the mill equals the amount leaving the mill. Hence, the steady-state amount, $m_{s s}$, of affected uranium in the mill remains constant, i.e., dm/dt $=0$. Steady state is achieved for large values of $t$, but for all practical purposes this occurs for times $\Im_{4} t_{\frac{1}{2}}$. For mills with halftimes of a few days or less, the mill output would achieve its maximum (steady-state) perturbation in a week or two. Consequently,

$$
\mathrm{m}_{\mathrm{ss}}=\mathrm{k} / \lambda \text {. }
$$

The limit of detection of reactor ore that is continuously fed into a mill can be determined in terms of the effective burnup, $\mathrm{B}$, of the ore and the steady-state concentration, $\mathrm{C}_{\mathrm{sS}}$, of the affected uranium. The ${ }^{235} \mathrm{U}$ wt. $\%$ of the mill output sample that is taken during steady state is given by

$$
\text { wt. }:=\left[C_{S S}(1-B / 100) 0.7107 / 100\right]+\left(1-C_{S S} / 100\right) 0.7107 \text {, }
$$

where $C_{S S}=m_{s s} / M=k / R$, and $C_{s S}$ and $B$ are in per cent. If the limit of anomaly detection is again assumed to be $0.7101 \mathrm{wt} . \frac{8}{8}{ }^{235} \mathrm{U}$, then Eq. (19) reduces to

$$
\mathrm{C}_{S \mathrm{~S}} \mathrm{~B} \geq 8.44\left(\frac{\%}{0}\right)^{2} \text {. }
$$


Equation (20), then, defines the detection limit of reactor uraniam where the affected ore is continuously fed into the mill and where the output is sampled when steady state is achieved. The frequency of mill sampling is unimportant in this scenario, so long as the duration of the continuous feed is longer than the sampling frequency, and so long as the frequency is considerably less than the time required to mine out the reactor zone.

As an example of this detection, if the reactor ore had an effective burnup of $10 \%$, then $C_{S S}$ would only have to be $0.8 \%$. A typical uranium mill might have a 4 -ton per day uranium output and $t_{t_{2}}=2 \mathrm{~d}$. Thus, the steady-state mass of affected uranium in the mill would be about $97 \mathrm{~kg}$, and the rate $\mathrm{k}$ at which it would be fed into the mill would be $34 \mathrm{~kg} / \mathrm{d}$. An average feed rate significantly below $34 \mathrm{~kg} / \mathrm{d}$ would not be jetected with the $0.7101 \mathrm{wt} . \%$ analytical sensitivity. Alternatively, the anomaly would go undetecter if the effective burnup were significant 1 yelow $10 \%$.

Blending of ores to some optimal mill-feed concentration is perhaps the best argument for reactor ore being proressed over a relatively long period of time. Mill-feed uranium concentrations are held at relatively constant values: typically between about 0.1 and $0.4 \%$ uranium. Hence, the time required for blending the high-grade reactor ore will be approximately equal to the minimum time it takes the aromalous ore to pass through the mill. Consider the following general case of ore blending: If there is some quantity, $H$, of high-grade reactor ore of grade $G(\stackrel{\sim}{>} 20 \%$ ) uranium, then this quantity must be mixed with a much larger quantity of lower grade ore in order to attain the proper mill-feed concentration, $g$. If $L$ is the final quantity of blended ore with mill-feed uranium concentration of $g$, and if $f$ represents the ratio of the diluent ore concentration to the final mill-feed ore concentration, then

$$
L=H(G-f g) / g(l-f) .
$$

For the assumed values of $\mathrm{G}=30 \%$ and; $=0.4 \%$, this relationship of $\mathrm{L}$ and $\mathrm{H}$ is shown graphically in Fig. 6 for various values of $f$. 


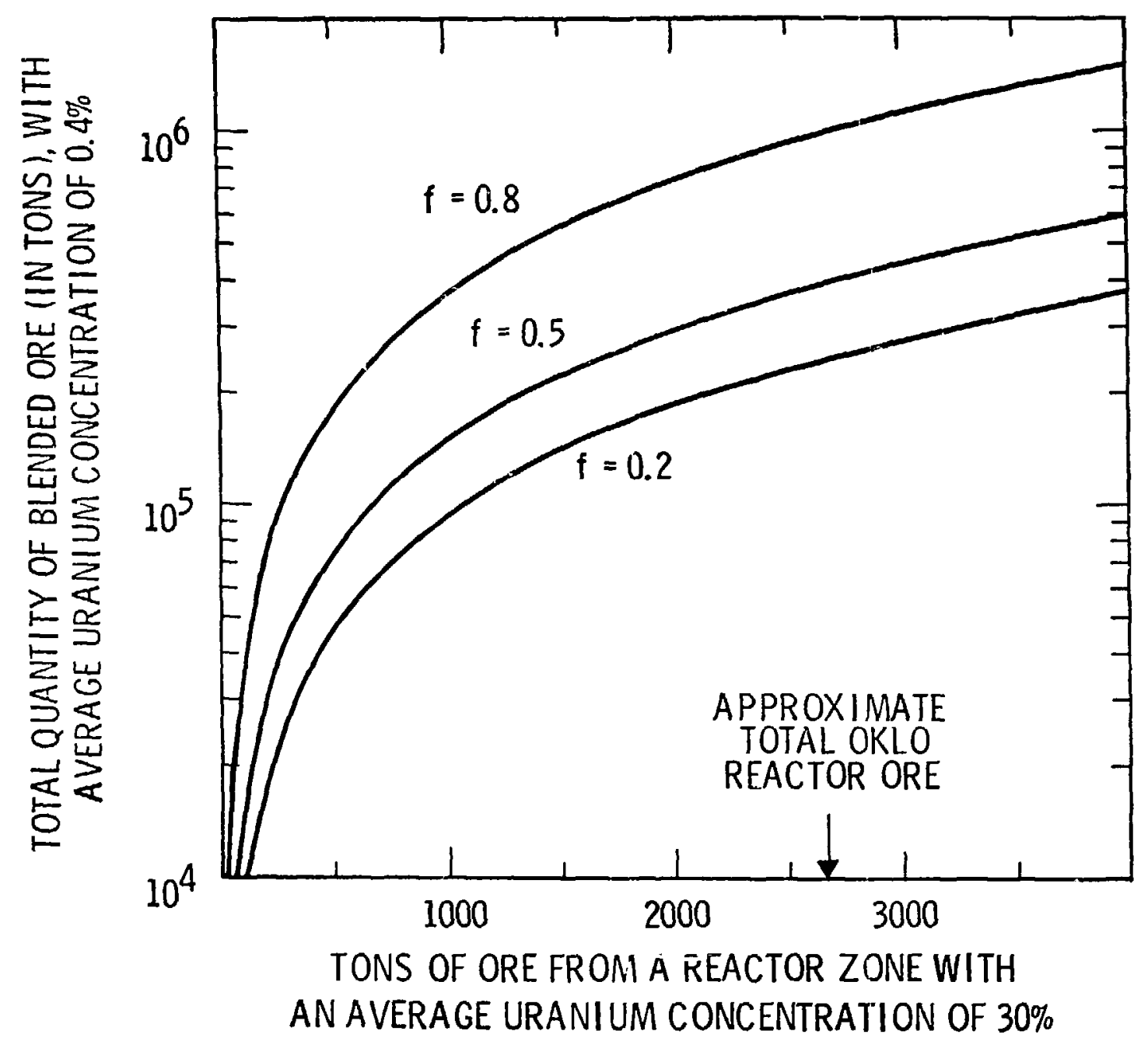

Fig. 6 .

The quantity of blended ore, $L$, with mill-feed uranium corcentration of $g=0.4 \%$, which is made up of $H$ tons of $30 \%$ ore from 
From Fig. 6 it is apparent that if the diluent ore is very low grade, i.e., $f \simeq 0.2$, then the reactor ore will be mixed in a relatively low total quantity of ore. This total quantity would nevertheless be $\sim 10^{5}$ tons for reactor systems similar in size to oklo, and would require months to be processed. Typical uranium mill throughputs are around $10^{3}$ tons of ore per day, so $₹ 100 \mathrm{~d}$ would be the duration of the anomaly throughput. The steady-state concentration $C_{S S}$ would, of course, be $\sim 80 \%$. Thus, from Eq. (20), the effective burnup of tne reactor system would only have to be $\Im 0.1 \%$ to ensure detection. By contrast, if the diluent ore had $80 \%$ ( $f=0.8$ i of the concentration of the mill feed, then the total quantity of blended ore would be $\sim 10^{6}$ tons. Such a quantity would probably require years to be processed, and the resulting $\mathrm{C}_{\mathrm{ss}}$ of $20 \%$ would be easily detected for values of $B \subsetneq 0.4 \%$.

For natural reactor ore that is continuously fed into a mill as a result of ore blending or limited mining, a general relationship can be derived for the detection of the anomaly. When the reactor ore feed is at steady state with the yellowcake product, $\mathrm{C}_{\mathrm{SS}}=(1-f) \times 100 \%$. Also, in most milling situations, the reactor ore grade would be much higher than the diluent ore grade, i.e., $G \gg f g$, and hence Eq. (21) simplifies to

$$
C_{3 S}=(1-f) \times 100 \% \frac{H G}{L g} \times 100 \%
$$

And substituting into Eq. (20) gives

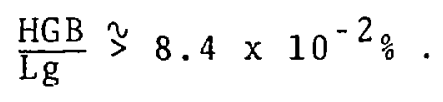

Equation (23) defines the limit of detection of a mined natural reactor in terms of the quantity, grade, and effective burnup of the reactor ore $(H, G$, and $B$, respectively) and the quantity and grade of the final ore it is diluted to ( $L$ and $g$, respectively). This detection assumes that the affected ore is fed into the mill at a relatively constant rate for a duration which is long compared to the mill sampling frequency. 
For example, consider a natural reactor one-twentieth the size of $0 k 10$, i,e., 30 tons of reactor uranium ore which has grade $G=30 \%$. If the processing mill has a required feed concentration $\mathrm{g}$ of $0.2 \%$, then $\mathrm{L}$ is 1 ikely to be about $6 \times 10^{4}$ tons (within a factor of $\sim 3$ ). Using Eq. (23), we see that the reactor system would be detected if its effective burnup was $>0.3 \%$. For a more optimistic burnup value between 1 and $10 \%$, the natural reactor would be even easier to detect. However, the timing involved in detecting such a small reactor system would be extremely critical. The $6 \times 10^{4}$ tons of ore that contain the 130 tons of highgrade reactor uranium ore would be processed in about two months. The type and frequency of mill sampling would then be very important, and the sampling and analysis delay time could possibly prevent detection until after complete exhumation. Clearly, there are many factors in mill sampling which must be balanced for effective monitoring.

\section{CONCLUSIONS}

The preceding arguments set limits for the detection of natural reactor uranium for various milling and sampling scenarios. Clear$1 y$, the cases presented for episodic feed or continuous feed of anomalous uranium into a mill represent hypothetical extremes. In actual mill operations, one would not expect a single "pulse" of reactor uranium through the mill or a constant feed rate over a long period. Reactor uranium ore would most likely be fed in some erratic fashion depending on mining and milling variables. However, the formulae derived above can be used to devise a mill monitoring plan and to estimate its effectiveness in detecting anomalous ore.

Equation (21) suggests that for a natural reactor system the size of oklo, many months would be required for processing of the affected ore. A rich ore zone such as this would be deliberately mined, stockpiled, and blended over a long time (compared to the mill half-time) so that the average grade of the mill feed would not deviate from the optimum concentration. Thus, some type of continuous feed situation would result, even though the isotopic 
anomaly in the yellowcake could fluctuate by an order of magnitude or more. But since the objective of mill monitoring is to detect the anomaly before complete exhumation of the natural reactor, the monitoring techniques should be designed to detect the first "pulses" of anomalous ore being processed, rather than relying on detection of the "steady-state" concentration.

For mills with long dilution half-times the anomaly output following a pulse of reactor ore would tend to be constant and slowly varying; for short half-times, the isotopic variations in the output would more closely reflect the erratic variations in the input of the reactor ore. Consequently, Figs. 3 and 5 indicate that mills with short half-times would require continuous sampling, and those with longer half-times could safely use grab sampling without sacrificing sensitivity.

Sampling frequency is an important consideration in monitoring sensitivity. But the frequency will no doubt be determined by the convenience of collection and shipment and by sample analysis limitations. It is estimated that samples could be conveniently collected and analyzed at a rate of one sample every 5 to 20 days. Sampling rates in excess of this would not be efficient, and less frequent sampling would result in total sampling and analysis times about equal to the time expected to mine out a small reactor zone. Since sampling frequencies will be determined somewhat arbitrarily, the mill half-time will dictate which type of sampling should be used. For $T / t_{\frac{1}{2}}$ values $飞 2$, grab sampling is sufficient; but for values $\Im 2$ continuous sampling is required (see Fig. 3). An actual sampling plan, then, is greatly dependent upon the operating characteristics of the individual mill. Mills servicing Precambrian vein-type uranium deposits should therefore be evaluated individually according to these monitoring criteria and calculations.

Having selected a sampling frequency and decided on continuous or grab sampling, the mill monitoring sensitivity can be determined. Equations (7) and (13) set the limits for detection of a first pulse of anomalous ore being processed. These limits represent the detection of the lowest possible product of the initial mill concentration of reactor-ore uranium and the effective burnup of the 
reactor ore. For situations where $B_{0}$ is larger than the limiting value, the anomaly would be more easily cetected. For most mill monitoring situations, the detection limit of $B C_{0}$ for a pulse can be maintained between about 10 and $100\left(\frac{\circ}{0}\right)^{2}$. Once the anomalous ore has been continuously fed into the mill for a relatively $1 \mathrm{cng}$ time, Eq. (20) establishes the limit of detection, i.e., about $8(\%)^{2}$ for steady state.

These equations can be used to test various milling and monitoring scenarios for the detectability of a natural reactor, but it is apparent that a natural fission reactor would be detected under most mill monitoring conditions. The first throughput of anomalous ore may not bo easily detected, but as the concentration of anomalous uranium in the mill approaches some steady-state value, the anomaly woulc almost certainly be detected. We know this should be so from the oklo experience. Anomalous ${ }^{235} \mathrm{U} /{ }^{238} \mathrm{U}$ ratios were detected for Oklo not at the mill output stage, but much later at the isotopic enrichment stage. Even after dilution during milling in Gabon and further processing in France, the oklo isotopic anomaly was easily detected by gas mass spectrometry. And even though several months passed before Oklo was identified, most of the reactor system remained intact.

It is important to remember that these detection predictions are very dependent upon the sensitivity of the isotopic measurement being employed. If the detection sensitivity for anomalous ${ }^{235} \mathrm{U}$ is worse than the $\sim 0.7101 \mathrm{wt} . \%$ value of gas mass spectrometry, then the factor 8.4 in Eqs. (7), (13), and (20) will be correspondingly increased. Conventional thermionic mass spectrometry, for instance, has a typical precision of $0.1 \%$, relative. And the threshold for detection of anomalous ${ }^{235} \mathrm{U}$ is about $0.709 \mathrm{wt} .8$, using the $3 \sigma \mathrm{cri}-$ terion. Thus, the factor 8.4 would be replaced by the factor 30 in Eqs. (7), (13), and (20), and the isotopic monitoring would be nearly four times less affective.

If, on the other hand, a more sensitive isotopic measurement is employed, the factor 8.4 could be correspondingly rediced. Conceivably ruthenium, palladium, or neodymium isotopic measurements could be used to detect an increment in these fission-product 
elements that results from a natural fission reactor. Ruthenium isotopic ratios, for instance, are far more sensitive to natural fission than are uranium isotopic ratios. This is because ruthenium is produced with a high yield in $235_{U}$ fission ( $\sim 17 \%$ of all fissions) and because the natural abundance of rutrenium is extremely low ( $~ 1 \mathrm{ppb}$ crustal average). Thus, a natural reactor ore with $30 \%$ uranium and only a $10^{-5_{\circ}}$ burnup of $235_{\mathrm{U}}$ will have a $101_{\mathrm{Ru}} /{ }^{100} \mathrm{Ru}$ ratio about ten times the natural ratio of $1.36 / 1$. Furthermore, this rutheniun isotopic increment would be essentially independent of any ${ }^{235} \mathrm{U}$ breeding accompanying $235_{U}$ burnup. Uranium isotopic measurement of natural breeder reactor ore, by contrast, would probably indicate nothing abnormal about the uranium.

While such fission product measurement techniques appear to have vastly superior sensitivities, they would not be practical for routine mill monitoring. First, the likelihood of a natural breeder reactor is much less than that of an oklo-type reactor system where a relatively small percentage of conversion occurred. Thus, a monitoring contingency for a natural breeder reactor is a secondary consideration. Second, the fate of fission-product ruthenium, palladium, and rare-earth elements in a uranium mill process is not known. These elements may be concentrated in certain mill byproduct or "tails" channels, but detailed experiments would have to be conducted for each mill in order to determine the path of these elements. Third, there is no convenient mill product that contains these elements as there is with uranium isotope monitoring and the yellowcake product. The element would have to be chemically separated and purified from some serondary mill product or effluent. Finally, the analytical techniques for measurement of the extremely small quantities of these elements (which must come from reasonably sized mill samples) are not routinely available. Such exacting measurement techniques are at best developmental and are not well suited for routine performance. If these analytical techniques become operational in the future, it would be appropriate to reevaluate the possibility of a fission-product monitoring scheme; but at present this type of monitoring is unfeasible. 
The mill monitoring techniques described herein have dealt with the detection of a "fossilized" reactor system similar to the oklo phenomenon. While study of other such intact systems would be most advantageous from the point of view of reactor physics uranium geochemistry, we have no guarantee that a natural reactor would remain relatively unperturbed. In fact, ore genesis studies of the northern Saskatchewan and Northern Territory, Australia, suggest that episodic redistribution of Proterozoic, vein-type uranium deposits may be common. 10,11 (In this regard, Okio is an "end member" example of an ore body with virtually no rearrangement.) Consequently, we might expect that ${ }^{235} \mathrm{U}$-depleted uranium from a disseminated reactor might cause a generalized yet subtle $235 \mathrm{U}$ depletion in a present-day ore body configuration. How successful would mill monitoring be in detecting such a situation? If we again consider a natural reactor system similar to oklo where there were $\sim 800$ tons of reactor uranium with an effective ${ }^{235} U$ depletion of $\sim 13 \%$, then there would be a total deficit of $\sim 0.7$ tons of ${ }^{235} \mathrm{U}$. Now if the reactor uranium were mixed with the total ore body which had 100 times more uranium (apparently the Jabiluka 2 ore body is one of the few vein-type deposits with uranium reserves over 100000 tons), then the resultant average $235_{U}$ depletion would be about $0.1 \%$, relative. In other words, the ${ }^{235} \mathrm{U}$ relative abundance would average about 0.7100 wt. $\%$ instead of the expected $0.7308 \mathrm{wt} . \%$. The ore body would no doubt have regions where the $235_{U}$ content would be significantly below this average or indisinguishable from normal, but it is likely that there would be long periods when the mill-feed uranium would average around $0.710 \mathrm{wt} . \% 235_{\mathrm{U}}$.

This abnormal $235 \mathrm{U}$ content would be detected in yellowcake samples if gas mass spectrometry was used; the threshold for anomaly detection is about $0.7101 \mathrm{wt} . \%$. It is clear, however, that there is little room for error with this scenario. If the ${ }^{235_{U}}$ burnup in the original reactor system were an order of magnitude less, the average ${ }^{235} \mathrm{U}$ depletion would be below detection. But the reactor dissemination would probably not be homogeneous within the ore body, anc a more anomalous region might still be detected. 
Given these analytical and dilution limitations, then, a disseminated natural reactor could be discovered with a mill monitoring program. Such a situation would be very interesting sinc: the migration behavior of reactor products would be influenced by bytrochemical factors rather than the retentivity of the uraninite matrix as at 0k1o.

The mined-out uranium vein deposits of the Great Bear Lake region of Northwest Territories, Canada, and the Shinkolobwe in Zaire would have been very promising locations for search for natural fission reactors. It is interesting to speculate on the possibility of past exhumation and milling of a natural reactor at these sites. Such an occurrence could have gone completely undetected because of the dilution factors involved in ore processing and because of the sampling and analytical limitations of past decades. Unfortunately, very few documented samples exist from depleted mines, and records or aliquots of old mill output are even less common. As a resuit, we may never know if past mining operations unwittingly lost evidence for this rarest of geological phenomena. It is hoped that if other fossilized or dispersed natural reactors exist, their discovery and elucidation will add to our knowledge of uranium geology, reactor waste-product geochemistry, and to the broader subject of the natural history of the earth.

\section{ACKNOWLEDGMENTS}

The author gratefully acknowledges the assistance of $G$. A. Cowan and E. A. Bryant in preparation of this document.

\section{REFERENCES}

1. G. A. Cowan, "A Natural Fission Reactor," Scientific American 235, 36 (1976).

2. R. Bodu, H. Bouzigues, N. Morin, and J. P. Pfiffelman, C. R. Acad. Sci. (Paris) 275D, 1731 (1972). 
3. M. Neuil1y, J. Bussac, C. Frejacues, G. Nief, G. Vendryes, and J. Yvon, C. R. Acad. Sci. (Pa $\because$ is) 275D, 1847 (1972).

4. The Oklo Phenomenon, Proceedings of Int. Atomic Energy Agency Symposium IAEA-SM-204, Liberville, Gabon, (1975) 650 p.

5. K. E. Apt and E. A. Bryant, "Criteria for Identifying Fossil Nuclear Reactors and Their Application to Saskatchewan," in Uranium in Saskatchewan, C. E. Dunn, Ed., Sask. Geol. Soc. Special Pub. No. 3, 193 (1976).

6. E. A. Bryant, G. A. Cowan, W. R. Daniels, and W. J. Maeck, "Oklo, an Experiment in Long-Term Geologic Storage," in Actinides in the Environment, A. M. Friedman, Ed., Amer. Chem. Soc. Symposium Series, No. 35, 89 (1976).

7. "Investigations of the Oklo Natural Fission Reactor: July 1975 through June 1976," K. E. Apt, Ed., Los Alamos Scientific Laboratory report LA-6575-PR (November 1976).

8. K. E. Apt, "The Search for Natural Fission Reactors," Abstracts of the 173rd National Meeting of the Amer. Chem. Soc., New Orleans, March, 1977.

9. G. A. Cowan and H. H. Adler, "The Variability of the Natural Abundance of $235 \mathrm{U}, "$ Geochim. Cosmochim. Acta 40, 1487 (1976).

10. R. D. Morton, "The Western and Northern Australian Uranium Deposits - Exploration Guides or Exploration Deterrents for Saskatchewan?" in Urarium in Saskatchewan, C. E. Dunn, Ed., Sask. Geol. Soc. Special Pub. No. 3, 211 (1976).

11. R. G. Dodson, R. S. Needham, P. G. Wilkes, R. W. Page, P. G. Smart, and A. L. Watchman, "Uranium Mineralization in the Rum Jungle - Alligator Rivers Province, Northern Territory, Austra1ia," in Formation of Uranium Ore Deposits, Proc. Int. Atomic Energy Agency Symposium 183, Athens, 551 (1974). 